\title{
AVALIAÇÃO DE SUBSTRATOS DE BAIXO CUSTO NA PRODUÇÃO DE BIOSSURFACTANTES DO TIPO LIPOPEPTÍDEOS
}

\author{
Í. W. L. DE FRANÇA ${ }^{1}$, J. A. M. $\operatorname{LEMOS}^{1}$, B. NOVAIS ${ }^{1}$, C. S. $\operatorname{LEMOS}^{2}$, V. M. M. \\ $\mathrm{MELO}^{3}$, H. B. SANTANA ${ }^{1}$, L. R. B. GONÇALVES ${ }^{1}$. \\ ${ }^{1}$ Universidade Federal do Ceará, Departamento de Engenharia Química \\ ${ }^{2}$ Universidade Federal do Ceará, Departamento de Engenharia de Alimentos \\ ${ }^{3}$ Universidade Federal do Ceará, Departamento de Biologia \\ Email para contato: 1rg@ufc.br
}

\begin{abstract}
RESUMO - Apesar das vantagens e aplicabilidade, os maiores entraves da produção de biossurfactantes em larga escala residem nos elevados custos de produção. Substratos (meio de cultivo) equivalem a 30\% dos custos de produção de biossurfactantes. A utilização de resíduos agroindustriais como substratos apresentam algumas vantagens como redução de custos no processo de produção dos biossurfactantes, além de reduzir possíveis impactos destes resíduos se fosse aplicados ao meio ambiente. O objetivo deste estudo visa avaliar substratos de baixo custo para a produção de biossurfactante como glicerol, soro de leite, suco de caju clarificado e óleo de girassol. Substratos como óleo de girassol e glicerol são apresentados como potenciais fontes de carbono para produção de biossurfactante pela cepa ICA56, obtendo concentrações de 870 mg.L $\mathrm{L}^{-1}$ e 1420 $\mathrm{mg} . \mathrm{L}^{-1}$ do produto de interesse, na sua forma bruta, respectivamente.
\end{abstract}

\section{INTRODUÇÃO}

Biossurfactantes constituem uma série de espécies químicas com propriedades tensoativas similares aos surfactantes químicos. São produzidos extracelularmente ou como parte da membrana celular de bactérias, leveduras e fungos. Os biossurfactantes apresentam algumas vantagens em relação aos surfactantes químicos: baixa toxidade, aceitabilidade ambiental, biodegradabilidade no solo e na água, possibilidade de produção por fontes renováveis, além de tolerância à condições extremas de temperatura, $\mathrm{pH}$ e força iônica, e serem biodegradáveis no solo e na água (PERREIRA et al. 2013). A aplicabilidade de biossurfactantes pode ser observada em diversos campos, como: agricultura, construção, indústrias alimentícias, de bebidas, papel, metal, têxtil, farmacêuticas e de cosméticos, entretanto a indústria petrolífera é apresentada como um dos principais mercados de interesse dos biossurfactantes (REIS et al. 2013).

As fontes de carbono utilizadas por micro-organismos para produção de biossurfactantes, normalmente apresentam custo elevado e podem inviabilizar economicamente a produção em larga escala. Substratos e os nutrientes do meio de cultivo equivalem a $30 \%$ dos custos de produção de biossurfactantes. A utilização de resíduos industriais como substratos para a produção de biossurfactante apresenta vantagens como a redução dos impactos ambientais ocasionados por estes resíduos e uma diminuição considerável nos custos produção de biossurfactantes (MAKKAR et al. 2011). 
Uma alternativa para aumentar a produção de biossurfactantes, bem como reduzir os custos da produção, reside na utilização de substratos não convencionais, tais como resíduos agroindustriais. Uma variedade de subprodutos ou resíduos, que incluem derivados de óleos vegetais, resíduos de amido, resíduos de destilaria de óleos e substâncias lácteas podem ser utilizados na produção de muitos metabólitos microbianos (MAKKAR et al. 2011).

Dentro deste panorama, este trabalho teve como finalidade a avaliação da produção de biossurfactante por cepa isolada de manguezal cearense (ICA56) utilizando resíduos agroindustriais (glicerol, soro de leite, suco de caju clarificado e óleo de girassol) como fonte de carbono.

\section{MATERIAIS E MÉTODOS}

\subsection{Micro-organismo e meio de estoque}

A cepa ICA56 foi previamente isolada de manguezal no município de Icapuí (Barra Grande) no estado do Ceará. Este micro-organismo foi apresentado como potencial produtor de biossurfactante por Lima (2013), por intermédio da identificação do gene $s f p$, responsável pela produção de surfactina, através de técnica de PCR (Reação em Cadeia da Polimerase). Esta linhagem pertence à coleção de bactérias do Laboratório de Ecologia Microbiana e Biotecnologia (LEMBIOTECH) do Departamento de Biologia da Universidade Federal do Ceará e foi gentilmente cedido para a realização do presente estudo. A linhagem foi mantida em meio APGE (ágar/peptona/ glicose/extrato de levedura) e repicada a cada 30 dias.

\subsection{Avaliação de substratos de baixo custo na produção de biossurfactante}

Avaliaram-se substratos não convencionais para a produção de biossurfactante. As fontes de carbono avaliadas foram: glicerol (SOUZA et al. 2012), soro de leite (FREITAS, 2013), suco de caju clarificado (OLIVEIRA et al. 2013) e óleo de girassol (VEDARAMAM \& VENKATESH, 2011). Em todos os meios de cultivo, a concentração inicial de carbono (substrato) foi padronizada para 20 g.L $\mathrm{L}^{-1} \mathrm{e}$ o cultivo foi realizado em agitador orbital a $30^{\circ} \mathrm{C}$ e $150 \mathrm{rpm}$, durante 48 horas. Meio mineral (BARRETO, 2011), contendo glicose como fonte de carbono, foi utilizada com finalidade de comparação às fontes de carbono não convencionais.

\subsection{Evolução temporal da produção de biossurfactante em agitador orbital}

Após avaliar fontes de carbono não convencionais pra produção de biossurfactante, foram realizados ensaio em agitador orbital utilizando as fontes de carbono que se apresentaram como promissoras na produção de biossurfactante. $\mathrm{O}$ ensaio em agitador orbital, para observar a influência do tempo na produção do biossurfactante, foi realizado a $30{ }^{\circ} \mathrm{C}$ e $150 \mathrm{rpm}$ durante 72 horas. Foram retiradas amostras em intervalos de tempo e então submetidas às análises de concentração celular, consumo de substrato, formação de produto e tensão superficial.

\subsection{Métodos Analíticos}

Determinação da biomassa: O crescimento celular foi obtido por método indireto de turbidimetria pela medida da densidade óptica a 600nm, conforme descrito em Giro et al. 
(2009).

Concentração de biossurfactante bruto: $\mathrm{O}$ biossurfactante bruto foi obtido do caldo fermentado por precipitação ácida, seguida de operações unitárias de centrifugação e secagem (PEREIRA et al. 2013).

Determinação da concentração de substrato: As concentrações de glicose, lactose, glicerol e frutose foram determinada por Cromatografia Líquida de Alta Eficiência (CLAE), segundo a metodologia descrita em Rocha et al. (2007). A quantidade de óleo de girassol consumida foi determinada por extração com hexano, segundo proposto por Vedaramam \& Venkatesh (2011).

Tensão superficial: Analisou-se o caldo fermentativo livre de células, com a utilização de um Tensiômetro (Krüss K6) a $30^{\circ} \mathrm{C}$.

Índice de Emulsificação ( $\left.\mathrm{E}_{24}\right)$ : Foi determinado de acordo com a metodologia proposta por Wei et al. (2005). A fonte hidrofóbica utilizada na formulação da emulsão foi óleo de motor SAE $15 \mathrm{~W}-40$.

\section{RESULTADOS E DISCUSSÃO}

A Tabela 1 apresenta os resultados de crescimento celular (biomassa) produção de biossurfactante, redução da tensão superficial do meio de cultivo e índice de emulsificação em óleo de motor, para cada substrato analisado.

Tabela 1 - Avaliação de resíduos agroindustriais na produção de biossurfactante pelo cultivo da cepa ICA56 em agitador orbital em 48 horas de cultivo.

\begin{tabular}{llllll}
\hline Substrato & Biomassa & Biossurf. & Tensão & Redução & E24 \\
& $\left(\right.$ g.L $\left.\mathbf{- 1}^{\mathbf{1}}\right)$ & bruto & Superficial & T.S. & $(\boldsymbol{\%})$ \\
& & $\left(\mathbf{m g . L ^ { - 1 } )}\right.$ & $\left(\mathbf{m N . m ^ { - 1 } )}\right.$ & $(\boldsymbol{\%})$ & \\
\hline Óleo de girassol & $2,69 \pm 0,55$ & $980 \pm 100$ & $36 \pm 0,00$ & $45,00 \pm 4,20$ & $90 \pm 0,15$ \\
Glicerol & $2,90 \pm 0,26$ & $1290 \pm 150$ & $28 \pm 0,25$ & $53,33 \pm 1,20$ & $92 \pm 0,26$ \\
Suco de caju & $2,31 \pm 0,21$ & $760 \pm 120$ & $30 \pm 0,30$ & $50,00 \pm 2,10$ & $91 \pm 0,46$ \\
Meio mineral & $2,48 \pm 0,31$ & $410 \pm 160$ & $33 \pm 0,00$ & $45,00 \pm 1,15$ & $79,6 \pm 0,16$ \\
Soro de leite & $1,67 \pm 0,30$ & $370 \pm 80$ & $31 \pm 0,00$ & $48,33 \pm 0,96$ & $70,5 \pm 0,59$ \\
\hline
\end{tabular}

* $\mathrm{E}_{24}$ : Índice de emulsfificação

Observa-se na Tabela 1 que o glicerol e óleo de girassol foram as fontes de carbono que mais favoreceram a produção de biossurfactante, apresentando concentrações de aproximadamente 1300 e $1000 \mathrm{mg} . \mathrm{L}^{-1}$. Apesar de baixa produção de surfactina em alguns substratos, tais como soro de leite $\left(370 \mathrm{mg} . \mathrm{L}^{-1}\right)$ e meio mineral $\left(410 \mathrm{mg} . \mathrm{L}^{-1}\right)$, observa-se que em todos os ensaios ocorreu redução da tensão superficial e formação de emulsão estável em óleo de motor. O biossurfactante produzido foi capaz de reduzir a tensão superficial da água 
de 72 para valores entre 28 e $36 \mathrm{mN} \cdot \mathrm{m}^{-1}$ e os índices de emulsificação foram superiores a $50 \%$. Estes resultados mostram a eficiência do biossurfactante produzido, mesmo em baixas concentrações.

Em glicerol, a tensão superficial do meio, após 48 horas de cultivo, foi de aproximadamente $28 \mathrm{mN} \cdot \mathrm{m}^{-1}$, valor próximo da tensão superficial de uma solução da surfactina padrão comercializada, que é $27 \mathrm{mN} \cdot \mathrm{m}^{-1}$ (GUDINA et al. 2010).

Zhu et al. (2013) avaliaram a produção de biossurfactante por cepa de Bacillus sp. e relataram que a maior produção de surfactina ocorreu com a utilização de glicerol como fonte de carbono, assim como foi observado no presente estudo. Faria et al. (2011) estudaram a produção e caracterização estrutural da surfactina produzida pela cepa Bacillus subtilis LSFM-05 em glicerol e relataram produção de $800 \mathrm{mg} . \mathrm{L}^{-1}$ de surfactina, valor inferior ao observado no presente estudo.

Vedaramam \& Venkatesh (2011) avaliaram a produção de biossurfactante por cepa de Bacillus subtilis em óleo de girassol e observaram a produção de surfactina em torno de 250 mg. $L^{-1}$, em 48 horas de cultivo. Chander et al. (2012) estudaram diferentes óleos vegetais como substrato para a produção de biossurfactante por Bacillus subtilis MTCC 441 e relataram que óleo de girassol foi o que mais estimulou o crescimento celular.

Suco de caju clarificado é relatado por Fontes et al. (2012) como um substrato promissor na produção de biossurfactante por Yarrowia lipolytica. Oliveira et al. (2013) relataram produção de aproximadamente $180 \mathrm{mg} . \mathrm{L}^{-1}$ de surfactina em suco de caju clarificado.

Soro de leite também foi utilizado por Joshi et al. (2008) para produção de biossurfactante por diferentes cepas de Bacillus sp. Estes autores observaram redução de $40 \%$ na tensão superficial durante o cultivo das cepas. Cagri-Mehmetoglu et al. (2012) mostraram que a cepa de Bacillus subtillis ATCC6633 foi capaz de consumir lactose, presente no soro de leite, e produzir cerca de $200 \mathrm{mg} . \mathrm{L}^{-1}$ de surfactina em 72 horas de cultivo. Pereira et al. (2013) estudaram diferentes fontes de carbono para a produção de surfactina, por Bacilus subtilis, e obervaram que, apesar do micro-organismo consumir lactose, esta não á fonte de carbono mais adequada para produção de biossurfactante.

Realizou-se ensaio em agitador orbital (72 horas) para produção de biossurfactante utilizando óleo de girassol e glicerol, tendo em vista analisar o comportamento do microorganismo no que se refere ao crescimento celular, consumo de substrato e formação do produto de interesse em função do tempo.

A Figura1 apresenta os resultados de crescimento celular, consumo de substrato, bem como formação de produto, durante o cultivo da cepa ICA56 em meio de cultivo contendo óleo de girassol como fonte de carbono. 


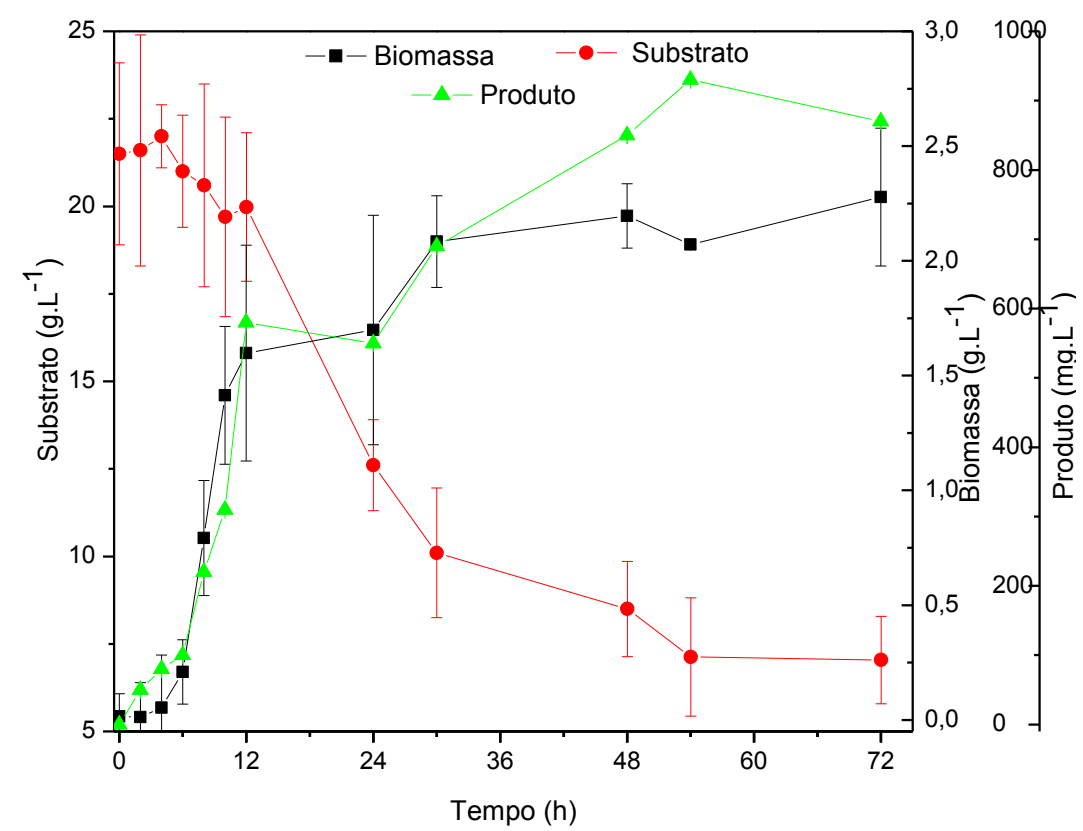

Figura 1 - Produção de biossurfactante pela cepa ICA56 em agitador orbital, 150 rpm e $30^{\circ} \mathrm{C}$ em meio de cultivo contendo óleo de girassol: Crescimento celular $($ a) consumo de substrato $(\bullet)$ e formação de produto $(\triangle)$.

Nas primeiras horas do ensaio, a baixa taxa de crescimento celular foi acompanhada de pouco consumo de substrato e limitada formação de produto. Após 48 horas de ensaio, houve uma redução no consumo de substrato, que foi refletido na concentração celular e formação de produto, que também apresentaram concentrações quase constantes. Atingiu-se concentração celular de aproximadamente 2,3 g.L.- A maior produção de biossurfactante (930 mg.L . $^{-1}$ ) ocorreu em 54 horas de cultivo. Esta produção de biossurfactante foi capaz de causar redução de $50 \%$ na tensão superficial do meio de cultivo.

Chander et al. (2012) estudaram diferentes óleos vegetais como substrato para a produção de biossurfactante por Bacillus subtilis MTCC 441 e relataram que óleo de girassol foi o que mais estimulou o crescimento celular, quando comparado a outros óleos vegetais. Vedaramam \& Venkatesh (2011) avaliaram a produção de biossurfactante por cepa de Bacillus subtilis MTCC2423 em óleo de girassol e observaram biomassa de aproximadamente 3,5 g.L. $\mathrm{L}^{-1}$ e produção de surfactina em torno de $600 \mathrm{mg}$. $\mathrm{L}^{-1}$, em 72 horas de cultivo. Apesar de menor crescimento celular, a concentração de surfactina produzida foi em torno de 35\% superior aos estudos realizados por Vedaramam \& Venkatesh (2011).

A Figura 2 apresenta os resultados de crescimento celular, consumo de substrato, bem como formação de produto, durante o cultivo da cepa ICA56 em meio de cultivo contendo glicerol como fonte de carbono. 


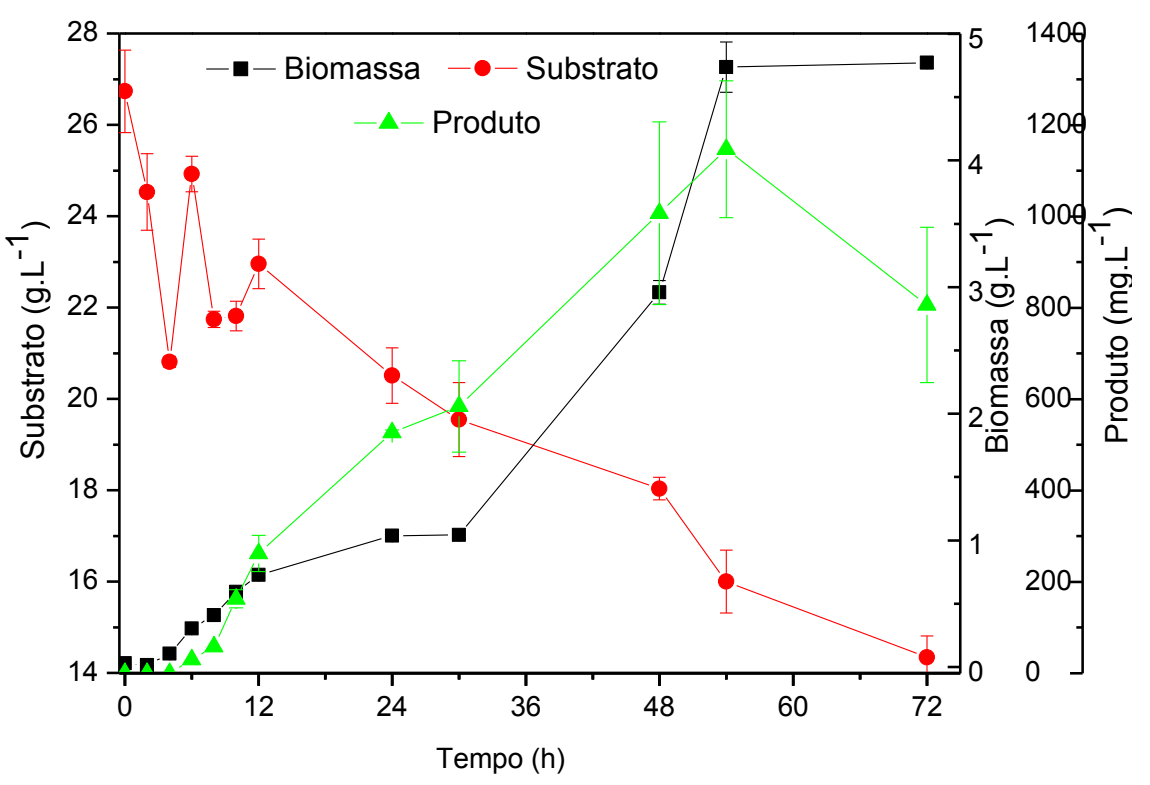

Figura 2 - Produção de biossurfactante pela cepa ICA56 em agitador orbital, $150 \mathrm{rpm}$ e $30^{\circ} \mathrm{C}$ em meio de cultivo contendo glicerol: Crescimento celular (a) consumo de $\operatorname{substrato}(\bullet)$ e formação de produto $(\triangle)$.

A maior concentração celular ocorreu em 54 horas de cultivo, correspondendo a aproximadamente 4 g. $\mathrm{L}^{-1}$, e este valor permaneceu praticamente constante em 72 horas. Observa-se na Figura 2 que nem todo o substrato foi consumido durante o cultivo. Aproximadamente 50\% do glicerol disponível foi convertido em biomassa e metabólitos pela cepa ICA56 (além da manutenção celular). SCHMIDELL et al. 2001 aponta que nem o substrato se esgota completamente quando a concentração celular é máxima, podendo ainda haver uma concentração residual desta substância, ao término do cultivo, como observado no presente estudo.

A maior produção de biossurfactante ocorreu em 54 horas de cultivo, correpondendo a aproximadamente $1150 \mathrm{mg} \cdot \mathrm{L}^{-1}$. A produção de surfactina foi responsável pela redução na tensão superficial da água de 72 para $28 \mathrm{mN}^{-1}$, equivalente a uma redução de $62 \%$, mostrando a eficiencia deste bioproduto como tensoativo. A partir de 24 horas de ensaio, a tensão superficial do meio de cultivo livre de células atingiu valores próximos a $30 \mathrm{~m} \cdot \mathrm{Nm}^{-1} \mathrm{e}$ permaneceu praticamente permanente até o final do cultivo da cepa (72 horas de incubação). Segundo Gudina et al. (2010) um eficiemte tensoativo é capaz de reduzir a tensão superficial da água de 72 para valores inferiores a $35 \mathrm{mN} \cdot \mathrm{m}^{-1}$.

Faria et al. (2011) estudaram a produção de surfactina pela cepa Bacillus subtilis em glicerol em biorreator de bancada de $10 \mathrm{~L}$ e relataram que a maior concentração de surfactina ocorreu em 72 horas de cultivo, que foi de $1320 \mathrm{mg} . \mathrm{L}^{-1}$. Zhu et al. (2013) avaliaram a produção de biossurfactante por cepa de Bacillus sp. em glicerol como fonte de e obtiveram produção de aproximadamente $1200 \mathrm{mg} . \mathrm{L}^{-1}$ de surfactina.

\section{CONCLUSÃO}

A utilização de resíduos agroindustriais é apresentada como uma potencial alternativa para produção de biossurfactante pela cepa ICA56, pois além da possibilidade de redução dos custos no processo, foram observados maiores rendimentos do que no meio sintético 
(mineral). Óleo de girassol e glicerol são apresentadas como potenciais fontes de carbono para produção de biossurfactante pela cepa ICA56, obtendo concentrações de $870 \mathrm{mg} . \mathrm{L}^{-1} \mathrm{e}$ $1420 \mathrm{mg} . \mathrm{L}^{-1}$ do produto de interesse, respectivamente.

\section{REFERÊNCIAS BIBLIOGRÁFICAS}

BARRETO, R. V. G., Prospecção de micro-organismos e genes envolvidos com a produção de biossurfactantes em solos de manguezais, 2011. Tese (Doutorado em Doutorado em Biotecnologia) - Rede Nordeste de Biotecnologia (RENORBIO) Universidade Federal do Ceará, 2011.

CAGRI-MEHMETOGLU, A.; KUSAKLI, S. Production of polysaccharide and surfactin by Bacillus subtilis ATCC 6633 using rehydrated whey powder as the fermentation medium. Journal Dairy Science, v. 95 (7) p. 3643-3649, 2012.

CHANDER, C. R. S; T. LOHITNATH; KUMAR, D. J. M; KALAICHELVAN, P. T. Production and characterization of biosurfactant from Bacillus subtilis MTCC441 and its evaluation to use as bioemulsifier for food bio-preservative. Advances in Applied Science Research, v. 3 (3) p. 1827-1831, 2012.

FARIA, A. F.; TEODORO-MARTINEZ, D. S.; BARBOSA, G. N. O.; VAZ, B. G.; SILVA, I. S.; GARCIA, J. S.; TÓTOLA, M. R.; EBERLIN, M. N.; GROSSMAN, M.; ALVES, O. L.; DURRANT, L. R. Production and structural characterization of surfactin (C14/Leu7) produced by Bacillus subtilis isolate LSFM-05 grown on raw glycerol from the biodiesel industry, Process Biochemistry, v. 46, p. 1951-1957, 2011.

FONTES, G. C.; RAMOS, N. M.; AMARAL, P. F. F.; NELE, M. ; COELHO, M. A. Z. Renewable resources for biosurfactant production by yarrowia lipolytica. Brazilian Journal of Chemical Engineering (Impresso) v. 29, p. 483-494, 2012.

FREITAS, M. F. M., Produção de $\beta$-galactosidase por Kluyveromyces lactis NRRL Y1564 em soro de leite e imobilização em quitosana, 2013. Dissertação (Mestrado em Engenharia Química) - Departamento de Engenharia Química, Universidade Federal do Ceará, Fortaleza, 2013.

GIRO, M. E. A.; MARTINS, J. J. L.; ROCHA, M. V. P.; MELO, V. M. M.; GONÇALVES, L. R. B. Clarified cashew apple juice as alternative raw material for biosurfactant production by Bacillus subtilis in a batch bioreactor. Biotechnology Journal, v. 4, p. 738-747, 2009.

GUDINA, E. J.; TEIXEIRA J, A.; RODRIGUES L. R.; Isolation and functional characterization of a biosurfactant produced by Lactobacillus paracasei, Colloids, Surfaces andBiointerfaces, v. 76 (1) p. 298-304, 2010.

JOSHI, S.; BHARUCHA, C.; JHA, S.; YADAV, S.; NERURKAR, A;. A. J. DESAI. Biosurfactant production using molasses and whey under thermophilic conditions, Bioresource Technology, vol. 99, p. 195-199, 2008.

LIMA, L. B., Frequência de bactérias produtoras de biossurfactantes lipopeptídeos em sedimentos de manguezais do Ceará, 2002. Dissertação (Mestrado em Ciências 
Marinhas Tropicais) - Intituto Ciências do Mar, Universidade Federal do Ceará, Fortaleza, 2002.

MAKKAR, R. S.; CAMEOTRA, S. S.; BANAT, I. M. Advances in utilization of renewable substrates for biosurfactant production. AMB Express, v. 1, p. 5-24, 2011.

OLIVEIRA, D. W. F.; FRANCA, I. W. L.; FELIX, A. K.; MARTINS, J. J.; GIRO, M. E.; MELO, V. M.; GONCALVES, L. R. Kinetic study of biosurfactant production by Bacillus subtilis LAMI005 grown in clarified cashew apple juice. Colloids, Surfurfaces and Biointerfaces, v. 101, p. 34-43, 2013.

PEREIRA, J. F. B.; GUDIÑA, E. J.; COSTA, R.; VITORINO, R.; TEIXEIRA, J. A.; COUTINHO, J. A. P.; RODRIGUES, L. R.; Optimization and characterization of biosurfactant production by Bacillus subtilis isolates towards microbial enhanced oil recovery applications, Fuel, v. 111, p. 259-268, 2013.

REIS, R. S.; PACHECO, G. J.; PEREIRA, A. G.; FREIRE, D. M. G. Biosurfactants: Production and Applications, Biodegradation - Life of Science, Dr. Rolando Chamy (Ed.), InTech, 2013, v. 01, p. 1-370, 2013.

ROCHA, M. V. P. Produção de biossurfactantes por fermentação submersa usando substrato não convencional. Dissertação (Mestrado em Engenharia Química) Departamento de Engenharia Química, Universidade Federal do Ceará (UFC) Fortaleza - Ceará, 2007.

SCHMIDELL, W.; LIMA, U. A.; AQUARONE, E.; BORZANI, W. Biotecnologia Industrial, ed.1, v. 2, p. 539, 2001.

SOUSA, M.; MELO V. M. M.; RODRIGUES, S.; SANT’ANA, H.B.; GONÇALVES, L. R. B. Screening of biosurfactant - producing Bacillus strains using glycerol from the biodiesel synthesis as carbon source. Bioprocess and Biosystems Engineering, v. 35, n. 6, p. 897-902, 2012.

VEDARAMAN, N.; VENKATESH, N. Production of surfactin by Bacillus subtilis MTCC 2423 from waste frying oils, Brazilian Journal of Chemical Engineering, v. 28, p. 175-180, 2011.

WEI, Y.; CHOU, C.; CHANG, J. Rhamnolipid production by indigenous Pseudomonas aeruginosa originating from petrochemical wastewater. Biochemical Engineering Journal, v. 27, p. 146-154, 2005.

ZHU, Z.; ZHANG, F.; WEI, Z.; RAN, W.; SHEN, Q. The usage of rice straw as a major substrate for the production of surfactin by Bacillus amyloliquefaciens XZ-173 in solidstate fermentation. Journal Environmental Manage, v. 127, p. 96-102, 2013. 